\title{
Elaboration of a spontaneous gluten-free sourdough with a mixture of amaranth, buckwheat and quinoa flours analyzing microbial load, acidity and pH
}

Carbó, Rosa; Universitat Politècnica de Catalunya, Department of Agri-Food Engineering and Biotechnology;

Gordún, Elena; Universitat Politècnica de Catalunya, Department of Agri-Food Engineering and Biotechnology;

Fernández, Antía; Universitat Politècnica de Catalunya, Department of Agri-Food Engineering and Biotechnology;

Ginovart, Marta; Universitat Politècnica de Catalunya, Department of Mathematics

Keywords: Baking technology, Bakery products, Lactic acid bacteria, Yeasts, Fermentation

\begin{abstract}
Pseudocereals are gluten-free, nutrient-dense raw materials that are being considered for the production of gluten-free products, especially bread. This study proposes a gluten-free sourdough formula based on equal amounts of amaranth, buckwheat and quinoa and with a dough yield of 250, and an elaboration method to obtain ripe sourdough. Sourdough was characterized in terms of microbiology, $\mathrm{pH}$ and total titratable acidity (TTA). The established protocol made it possible to obtain a spontaneous ripe sourdough with lactic acid bacteria (LAB) populations of $9.60 \pm 0.02 \mathrm{Log} C F U / g$ and total yeast and non-

Saccharomyces yeast populations (lysine positive) of $7.91 \pm 0.15$ and $7.52 \pm 0.10 \mathrm{Log}$ $\mathrm{CFU} / \mathrm{g}$, respectively. Great $\mathrm{pH}$ stability and TTA were maintained in the ripe sourdough phase, with values of $4.04 \pm 0.02$ and $18.39 \pm 0.56 \mathrm{ml} \mathrm{NaOH} 0.1 \mathrm{M} / 10 \mathrm{~g}$, respectively, at the time of the next refreshment. The use of this sourdough could be an interesting alternative for the production of not only gluten-free bread but also other gluten-free products.
\end{abstract}




\section{INTRODUCTION}

Celiac disease is an immune-mediated enteropathy triggered by the ingestion of gluten in genetically susceptible individuals, with a prevalence of approximately $1 \%$ worldwide (Catassi and Fasano, 2008). Despite advances in understanding celiac disease pathogenesis and diagnosis and potential development of novel therapies, at present the only safe and effective treatment for this disease is complete exclusion of gluten-containing products from the diet (Catassi and Fasano, 2008; Hüttner and Arendt, 2010).

Gluten-free systems have been greatly improved by evaluating different ingredients, additives and technologies. Nevertheless, the development of gluten-free products is still a technological challenge because currently no single raw material, ingredient or additive can completely replace gluten. Bread is the most studied of all gluten-free products but it is not able to satisfy the majority of celiac consumers (Capriles et al., 2016). Most commercially available gluten-free breads are characterized by poor taste and flavor, and are made with non-fortified refined ingredients, which have a very low content of dietary fiber and micronutrients and a high glycemic index. Moreover, being mainly based on starches, these products undergo fast staling owing to starch retrogradation (Moroni et al., 2009).

Gluten-free bread quality can be enhanced through sourdough fermentation because of its wellrecognized ability to improve flavor, texture, shelf life and nutritive value of bread. The advantages of using sourdough in bread-making are due to the fermentative and acidifying activity of lactic acid bacteria (LAB) and yeasts selected from the spontaneous microbial population grown during sourdough back-slopping. These microorganisms perform special metabolic activities -lactic acid fermentation, proteolysis, exopolysaccharides production and synthesis of compounds with antimicrobial activities- that make it possible to enhance gluten-free bread properties such as texture, flavor, taste, volume and nutritional quality (Moroni et al., 2009). Production of $\mathrm{CO}_{2}$ by heterofermentative $\mathrm{LAB}$ and yeasts influences the leavening process of the final dough, improving bread softening. Interaction between LAB and yeasts contribute to improve texture, concentration of volatile compounds and microbiological shelf life of the dough (Siepmann et al., 2018). Another main advantage of incorporating sourdough in gluten-free bread-making is the improvement of nutrient bioavailability. Phytic acid is considered an antinutritional factor as it strongly binds to metallic cations of $\mathrm{Ca}, \mathrm{Fe}, \mathrm{K}, \mathrm{Mg}, \mathrm{Mn}$ and $\mathrm{Zn}$, making them insoluble and thus unavailable for nutrition. The use of sourdough could be a resource for decreasing phytate concentration due to the presence of phytate active LAB and yeasts (Karaman et al., 2018). Furthermore, sourdough fermentation contributes to the reduction of the glycemic index of bread. This could be highly beneficial since there is a high incidence of type I diabetes in individuals with celiac disease who should consume low-glycemic index products (Novotni et al., 2012; Capriles et al., 2016). 
Finally, sourdough fermentation is a natural tool to extend bread shelf life because it can prevent microbial spoilage and retard bread staling. In fact, sourdough associated LAB produce many antimicrobial compounds such as organic acids, ethanol, $\mathrm{CO}_{2}$ and fungicins with activities against common bread spoilage organisms (Hassan et al., 2016). Moreover, bread staling delay is partly achieved thorough not only reduction of starch retrogradation as a result of amilolitic activity from sourdough LAB, but also expolysaccharide production by heterofermentative LAB (Galle et al., 2012). Therefore, incorporation of sourdough in gluten-free bread-making can contribute to avoiding the use of expensive chemical preservatives (Novotni et al., 2012) and will satisfy the request of consumers who demand a clean label. Elaboration processes and nutrient-dense ingredients (e.g. pseudocereals) are currently being tested to improve sensory and nutritional characteristics of gluten-free breads and enhance preservation and durability (Collar et al., 2015; Witczak et al., 2016).

Some researchers use different gluten-free flours, in addition to rice and corn, for sourdough making, cereal such as sorghum or millet (Galle et al., 2012; Akinola and Osundahunsi, 2017); pseudocereals such as amaranth, buckwheat, teff or quinoa (Sterr et al., 2009; Rühmkorf et al., 2012; Wolter et al., 2014; Rizzello et al., 2016); some legumes (Curiel et al., 2015); or others such as cassava or chestnut (Vogelmann et al., 2009; Aguilar et al., 2016); even some of them in germination form (Ogunsakin et al., 2015; Montemurro et al., 2019). All these flours provided nutrients that help the growth of the microorganisms. It has been reported that adding sourdough and some of these gluten-free flours has effect on bread quality (Campo et al., 2016; Rinaldi et al., 2017). Several protocols include the addition of LAB at the beginning of the sourdough (Marti et al., 2015) in order to ensure rapid dominance; some of them, inoculate strains from previous sourdough in order to take advantage of the characteristics of autochthonous strains (Picozzi et al., 2015). But there are procedures in which the fermentation occurs spontaneously, favoring the growth of autochthonous microorganisms (Gordún et al., 2015). Technological factors such as the frequency of the refreshments and the percentages of sourdough used are different depending on the procedures. Refreshments are proposed every 5 or 6 hours, and up to 24 hours, adding very different percentages of sourdough, ranging from 10, 20 and up to 40\% (Aguilar et al., 2016). In spite of the current knowledge of gluten-free spontaneous sourdough, more efforts are needed to establish basic criteria of sourdough elaboration protocol and the behavior of the raw ingredients used. This study aims to formulate a gluten-free sourdough based on pseudocereals and proposes an elaboration method for it. The effectiveness of the formulation and elaboration method was assessed by an experiment in which the resulting sourdough was characterized in terms of $\mathrm{pH}$, total titratable acidity (TTA) and microbial population (total yeasts, non-Saccharomyces yeasts and $\mathrm{LAB})$. 


\section{MATERIALS AND METHODS}

\section{Ingredients}

Three types of commercial organic pseudocereals were used for elaboration of spontaneous glutenfree sourdough. Amaranth seeds (Amaranthus spp.) were provided by Bioprasad (Spain) and grounded using a Perten 3100 laboratory grinder with a $0.8 \mathrm{~m}$ sieve; stone-ground whole buckwheat (Fagopyrum esculentum) flour was provided by Rincón del Segura (Spain); and quinoa flour (Chenopodium quinoa) by Salutef (Spain). All products were certified as gluten-free ( $<20 \mathrm{mg}$ gluten/kg, Commission Regulation (EC) $n^{\circ} 41 / 2009$ ). Items from the same manufacturing batch were used and the pseudocereal flours were stored at room temperature, sheltered from light.

\section{Formulation and procedure of gluten-free sourdough making with pseudocereal flours}

Gluten-free sourdough was formulated using equal amounts of the three pseudocereal flours: amaranth, buckwheat and quinoa, and with a constant dough yield of 250 (DY = [flour weight + water weight] x 100/ flour weight) (Figure 1). The sourdough making procedure consisted of an initial phase of immature ferment that included five stages of dough fermentation at $30{ }^{\circ} \mathrm{C}( \pm 0.2$ $\left.{ }^{\circ} \mathrm{C}\right)$ and four periods of blockage at $5{ }^{\circ} \mathrm{C}\left( \pm 0.2^{\circ} \mathrm{C}\right)$ prior to daily refreshment or back-slopping of the mature or ripe sourdough. This procedure was previously tested to fix a number of parameters such as a dough yield of 250 in order to obtain a fluid dough consistency. Previously fermented dough was used as a starter for the next dough, and the duration of the fermentation step at $30{ }^{\circ} \mathrm{C}$ required to reach a $\mathrm{pH}$ of 4.0-4.2 was tested. Finally, it was verified that typical mother dough microbiota (LAB and yeast) was obtained (results not shown).

The protocol of the proposed formulation and procedure is described in Figure 1. At the same time and under identical conditions, three sourdoughs were made in order to verify the designed protocol. To verify it, three sourdoughs were made simultaneously under identical conditions. The pseudocereal flours used at each step were mixed with water $\left(30^{\circ} \mathrm{C}\right)$ and kneaded using a kneader (Kenwood, model KM 336) at $200 \mathrm{rpm}$ for 2 min. Once the initial doughs were obtained, the first stage of fermentation started and lasted $24 \mathrm{~h}$ at $30^{\circ} \mathrm{C}$ until reaching a $\mathrm{pH}$ of 4.0-4.2. At that moment, an aliquot of each fermented dough (also called immature sourdough o pre-ferment) was mixed again with the pseudocereal flours and water. Fermentation times to obtain immature ferment at $30{ }^{\circ} \mathrm{C}$ were initially $16 \mathrm{~h}$ and then $6 \mathrm{~h}$. Blocking times at $5{ }^{\circ} \mathrm{C}$ were flexible, ranging from $18 \mathrm{~h}$ to $66 \mathrm{~h}$. After these steps of fermentation-blocking-renovation, daily refreshment of the already ripe sourdough was performed for 4 days. The percentage of ripe sourdough used as inoculum in the refreshments was $30 \%$ of the total dough weight, and fermentation time at $30{ }^{\circ} \mathrm{C}$ and microbial activity blocking time at $5{ }^{\circ} \mathrm{C}$ were $6 \mathrm{~h}$ and $18 \mathrm{~h}$, respectively. 


\section{Measurements of flour and mature sourdough}

Acidity. During the making of the three sourdoughs, $\mathrm{pH}$ and TTA were measured on dough samples taken before and after each nutrient renewal and at the end of the fermentation stage. $\mathrm{pH}$ was also determined after each blocking stage prior to refreshment. For all determinations, two independent measurements were taken on each sample and means were calculated.

The $\mathrm{pH}$ was measured directly in the dough with a glass electrode of a $\mathrm{pH}$ meter (Crison Instruments S.A., Spain) and in the aqueous preparation of $10 \mathrm{~g}$ dough samples blended with $90 \mathrm{ml}$ of distilled water used to determine TTA. These measurements were called "Direct $\mathrm{pH}^{\text {" and }}$ "Diluted $\mathrm{pH}$ ", respectively.

TTA was determined by suspension of the doughs (10 $\mathrm{g}$ of dough diluted in $90 \mathrm{ml}$ of distilled water) by an acid-base titration with $0.1 \mathrm{~mol} / \mathrm{l} \mathrm{NaOH}$ to $\mathrm{pH} 8.5$ (at least $20 \mathrm{sec}$ ) under shaking. TTA was expressed as the $0.1 \mathrm{~mol} / \mathrm{l} \mathrm{NaOH}$ volume used.

Microbial dynamics of yeast and LAB. Total yeasts, lysine positive yeasts (also called nonSaccharomyces yeasts) and LAB present in the three pseudocereal flours and dough samples (preserved at $4{ }^{\circ} \mathrm{C}$ ) before renewal were analyzed at different steps of the sourdough making process. To this purpose, $10 \mathrm{~g}$ of flour or dough was homogenized with $90 \mathrm{ml}$ of saline solution ringer $1 / 4$ (Sharlab, Spain) under shaking for 2 min. Decimal dilutions were made using the same solution, and microbiological seeding was performed with selective culture media on agar plates. Total yeast count was carried out on WL nutrient agar supplemented by $0.5 \mathrm{~g} / \mathrm{l}$ chloramphenicol (Scharlab, Spain), non-Saccharomyces yeasts on lysine agar (Scharlab, Spain) and LAB on ManRogosa-Sharpe agar (MRS agar) (Scharlab, Spain) supplemented by 15\% grape juice, 15\% tomato juice, $20 \mathrm{~g} / \mathrm{l}$ maltose and $75 \mathrm{mg} / \mathrm{l}$ cyclohexamide (pH: 5.5). Yeasts were incubated for 5 to 10 days at $27^{\circ} \mathrm{C}$, and $\mathrm{LAB}$ were incubated for 4 to 5 days at an atmosphere of reduced oxygen at less than 10\% using a candle jar. Countable plates, between 15 and 150 colonies on WL nutrient or lysine agar, and between 30 and 300 colonies on MRS agar, were used to quantify the microbial population.

\section{RESULTS AND DISCUSSION}

\section{pH and TTA}

Average $\mathrm{pH}$ values (direct) of the three replicas of the sourdoughs are shown in Figure 2. Dough $\mathrm{pH}$ (mixing amaranth, wheat and quinoa flours) decreased from 6.35 to 4.12 after 24 hours of fermentation at $30^{\circ} \mathrm{C}$. However, several previous gluten and gluten-free sourdough studies reported different results. For example, Harth et al., (2016) also obtained an initial decrease of 2 pH units in spontaneous sourdough elaborated in laboratory with barley flour, whereas sourdough with 
chestnut flour needed 48 hours at $25{ }^{\circ} \mathrm{C}$ (Aguilar et al., 2016) or up to 72 hours at $30{ }^{\circ} \mathrm{C}$ with amaranth flour alone (Sterr et al., 2009). Therefore, it is deduced that the protocols and recipes used to make sourdoughs are responsible for the differences in the $\mathrm{pH}$ decrease. Throughout the immature sourdough phase ( $24 \mathrm{~h}-160 \mathrm{~h}$ ), average values and standard deviations of $\mathrm{pH}$ before and after each nutrient renewal were $4.07 \pm 0.06$ and $4.97 \pm 0.16$, respectively. During the ripe sourdough phase (166 h - 262 h), the $\mathrm{pH}$ was stable, with average values before and after refreshments of $4.04 \pm 0.02$ and $5.02 \pm 0.03$, respectively. The behavior of the average $\mathrm{pH}$ values was cyclical and very regular during daily refreshments, i.e. an approximate increase of $1 \mathrm{pH}$ unit at each refreshment step. The established $\mathrm{pH}$ value was reached after $6 \mathrm{~h}$ of fermentation at $30{ }^{\circ} \mathrm{C}$ and remained stable during activity blocking $\left(5^{\circ} \mathrm{C}\right)$ until the next refreshment.

The $\mathrm{pH}$ values determined directly in the dough, "Direct $\mathrm{pH}$ ", and those determined in $10 \mathrm{~g}$ of dough / $90 \mathrm{ml}$ of distilled water, "Diluted $\mathrm{pH}^{\circ}$, showed a very high linear correlation, with a Pearson correlation coefficient equal to 0.997. It can be confirmed that, in a high hydration glutenfree sourdough, it is feasible to monitor direct $\mathrm{pH}$ instead of diluted $\mathrm{pH}$ because of the greater simplicity and speed of the former, as demonstrated in other works (Aguilar et al., 2016; Cappa et al., 2016; Rizzello et al., 2016).

Average TTA values of the three replicas of the sourdoughs are also shown in Figure 2. Immediately after the ingredients were mixed, the initial TTA was $2.58 \mathrm{ml}(0.1 \mathrm{M} \mathrm{NaOH} / 10 \mathrm{~g}$ dough). After $24 \mathrm{~h}$ of fermentation at $30{ }^{\circ} \mathrm{C}$, TTA reached a value of $19.09 \mathrm{ml}$. Before renewing nutrients and throughout the immature sourdough phase ( $24 \mathrm{~h}$ - $160 \mathrm{~h}$ ), average values and standard deviations of $19.53 \pm 1.67 \mathrm{ml}$ were recorded; after renewal, values were $8.55 \pm 1.42 \mathrm{ml}$. During the ripe sourdough phase (166 h - $262 \mathrm{~h}$ ), daily refreshments were followed by fermentation at $30{ }^{\circ} \mathrm{C}$ for $6 \mathrm{~h}$. Average values and standard deviations of TTA before and after refreshments were $18.15 \pm$ $0.18 \mathrm{ml}$ and $7.96 \pm 0.09 \mathrm{ml}$, respectively. Like $\mathrm{pH}$, TTA had a cyclical behavior during daily refreshments, with an approximate variation of 10 units at each refreshment step. These values are lower than those reported by other authors who work with gluten-free flours (Sterr et al., 2009; Rühmkorf et al., 2012). Vogelmann et al., (2009) found that pH and TTA values of ripe sourdoughs differed depending on the fermentation substrate. Eleven sourdoughs made with eleven cereals and pseudocereals were studied. The dough with quinoa reached the highest TTA value, followed by amaranth and finally wheat, buckwheat and the remaining seven. The fact that $\mathrm{pH}$ and TTA values in the present work coincide and differ, respectively, with those obtained by other authors could be explained by the lower buffer capacity obtained from the mixture of flours used. Rühmkorf et al., (2012) showed that quinoa and, to a lesser extent, buckwheat have a good buffering capacity when used separately. Some ingredients present in the flour, such as proteins, phytate or ash, also have a good buffering capacity. It has been shown that TTA is correlated with the phytate concentration (Hammes et al., 2005) and that the action of ash as a buffering agent is due to the higher 
concentration of minerals such as iron, sodium, potassium, magnesium and phosphorus (Salovaara and Valjakka, 1987).

\section{LAB and Yeasts}

$\mathrm{LAB}$ and total yeast counts were observed to be lower in amaranth flour than in quinoa and buckwheat flours ( $<2$ Log CFU / g of LAB and yeasts). Quinoa and buckwheat flours had initial LAB counts of 3.36 and 3.12 Log CFU / g, respectively. Regarding total yeasts, populations of $<2$ Log CFU/g in quinoa flour and 2 Log CFU/g in buckwheat flour were obtained. Counts for both microbial groups were quite similar to those found in wheat flour (Van Kerrebroeck et al., 2016). Gram-positive (e.g. Bacillus sp) and Gram-negative (e.g. Pseudomonas sp and Enterobacteriaceae) bacteria populations had also been found but disappeared as sourdough fermentation progressed and pH decreased (Minervini et al., 2014).

$\mathrm{LAB}$, total yeast and non-Saccharomyces yeast counts are shown in Table 1. The first microbiological control of the three replicas of the sourdoughs carried out after $24 \mathrm{~h}$ of fermentation at $30{ }^{\circ} \mathrm{C}$ revealed an average value and standard deviation of LAB counts of $9.54 \pm$ $0.14 \mathrm{Log}$ CFU /g. The viable population of LAB was high at the beginning and also throughout the entire process, in which constant counts were maintained both in the immature sourdough ( $24 \mathrm{~h}, 88$ $\mathrm{h}$ and $160 \mathrm{~h}$ ) and ripe sourdough (208 h and $256 \mathrm{~h}$ ) phases. Average values and standard deviations of LAB counts in the immature and ripe sourdough phases were 9.55 $\pm 0.16 \mathrm{Log}$ CFU / g and 9.60 $\pm 0.03 \mathrm{Log} \mathrm{CFU} / \mathrm{g}$, respectively. These figures were similar to those obtained for gluten-free sourdoughs by other authors (Sterr et al., 2009), even using LAB starter (Rühmkorf et al., 2012; Rizzello et al., 2016). The LAB colonies observed on MRS agar plates had a uniform morphological appearance: they were white, circular and bright (Figure 3).

Unlike the LAB count, the total yeast count grown on WL nutrient agar increased throughout sourdough making (Table 1). The first control carried out after $24 \mathrm{~h}$ of fermentation at $30{ }^{\circ} \mathrm{C}$ showed an average value and standard deviation of $4.64 \pm 0.18 \mathrm{Log}$ CFU / g. Yeast counts increased, reaching values of $\geq 7$ Log CFU / g in the immature sourdough phase (88 h, $160 \mathrm{~h}$ ) and 8.21 CFU / g in the ripe sourdough phase (208 h, 256 h).

The LAB:total yeast ratio obtained in the ripe sourdough phase (256 h) was 10:1, a proportion comprised in the wide range found in the sourdoughs prepared with both gluten and gluten-free flours (Lhome et al., 2015; Aguilar et al., 2016; Harth et al., 2016). The high dough yield (250) and the proportion of inoculum used (30\%) contributed to the balance between the two groups of microorganisms. It has been shown that high dough yield values $(\geq 250)$ favor LAB growth in 24$48 \mathrm{~h}$ (Minervini et al., 2014). On the other hand, the high concentration of inoculum used in refreshments facilitated the maintenance of high yeast counts and helped control the $\mathrm{pH}$ during fermentation (Brandt et al., 2004). 
The average count and standard deviation of the non-Saccharomyces yeast group, grown on lysine agar, was $4.62 \pm 0.17 \mathrm{Log} \mathrm{CFU} / \mathrm{g}$ at $24 \mathrm{~h}$ of fermentation. This group increased significantly to reach values around 7.5 Log CFU / g, remaining constant in the immature sourdough phase (160 h) and the ripe sourdough phase (208 h and 256 h). Gordún et al., (2015) reported that the high nonSaccharomyces yeast group value at the beginning of sourdough preparation was related to the addition of different non-essential ingredients. In the present study, the evolution of this group was inverse. This yeast growth could be due to the nutrients in the flours used.

WL nutrient agar and lysine agar made it possible to obtain total yeast counts and lysine positive yeasts (or non-Saccharomyces yeasts), respectively. The difference between both groups allows the concentration of the lysine negative yeast group, which includes among other genera Saccharomyces, to be known. This information is very useful because the different yeast groups are related to the dough texture observed during the making of the sourdough (Figure 4, Table 1). At $24 \mathrm{~h}$ of fermentation at $30{ }^{\circ} \mathrm{C}$, the dough had a spongy appearance and a greater volume. In this control, the lysine negative yeast group represented practically $7 \%$ of the total yeast count, decreasing to $4.5 \%$ in a subsequent control. In the next stages of the immature sourdough phase, the dough barely sponged because very few $\mathrm{CO}_{2}$ bubbles formed. Swelling was recovered in the ripe sourdough phase and the dough increased in volume with the first refreshments. However, in the last two refreshments, after $6 \mathrm{~h}$ of fermentation at $30{ }^{\circ} \mathrm{C}$, the dough could not maintain the volume reached, which decreased. The difficulty of retaining gas in sourdough made with pseudocereals due to lack of gluten has been described (Marti et al., 2015). In the ripe sourdough phase, the lysine negative yeast count increased, becoming the dominant group in the last refreshment, where it represented $80.6 \%$ of the total yeast count. The increase of the lysine negative yeast group can be considered responsible for the increase of the total yeast population.

Two morphology types of yeast colonies were found (Figure 3). A first type of colony was observed on lysine agar (belonging therefore to the non-Saccharomyces group) and on WL nutrient agar. This type of colony was white, filamentous and with an umbonate center elevation. The second type of colony was only observed on WL nutrient agar (belonging therefore to the lysine negative yeast group), was circular and smooth, and had a creamy coloration and an umbonate center elevation too. These two colonies showed pinpoint or negligible growth on lysine agar. Lysine agar medium uses L-lysine to provide organisms with a source of nitrogen, and was first used to distinguish wild yeasts in the brewing industry (Walters and Thiselton, 1953). Currently, it is used to control contamination in the manufacture of baker's yeast. Its application in sourdough allows lysine positive yeasts to be tracked (Gordún et al., 2015, 2017). In the present study, a type of non-Saccharomyces filamentous yeast was developed with stable high growth rates during sourdough making. Both lysine positive and negative yeasts participated in sourdough fermentation. Moreover, some lysine positive genera may find potential use in the baking industry because of their interesting aroma profiles (Aslankoohi et al., 2016). 


\section{Protocol for making sourdough}

The pH, TTA, LAB and yeast population results (Figure 2, Table 1) demonstrate that the mixture of equal proportions of amaranth, buckwheat and quinoa is a viable formulation for gluten-free sourdough. Additionally, the use of these ingredients provides bakery products with a greater diversity of nutrients, i.e. those found in these flours (USDA Food Composition Databases) and those generated during sourdough fermentation (Di Cagno et al., 2008; Arendt et al., 2011; Hager et al., 2012).

The proposed protocol (Figure 1) fulfills all the necessary conditions. The dough yield of 250 in the two phases (immature and ripe) of sourdough making provided a fluid consistency and may have favored the development of $\mathrm{LAB}$ and yeast populations. In the immature sourdough phase, the 5 stages of refreshment, fermentation time at $30{ }^{\circ} \mathrm{C}$ until reaching $\mathrm{pH} 4$ and activity blocking at $5{ }^{\circ} \mathrm{C}$ allowed TTA to be consolidated and favored the development of LAB and yeast populations capable of overcoming cooling stages up to $66 \mathrm{~h}$. In the ripe sourdough phase, maturity was evaluated by performing daily refreshments for 4 days, and constant acidification values (pH, TTA) were obtained. It has been shown that to keep TTA values constant it is important, among other things, to block fermentation without delay when a specific $\mathrm{pH}$ value is reached. At each step, the time required to reach the established $\mathrm{pH}$ value (4.0) is conditioned, among other factors, by the percentage of previous sourdough added. The increase of 30 to $40 \%$ of previous sourdough in one of the steps of immature sourdough, allowed the shortening of the necessary time, going from 16 to 6 hours. Good LAB:total yeast ratios (100 to $208 \mathrm{~h}$ and 10 to $256 \mathrm{~h}$ ) and clear leavening capacity were verified. However, in this phase leavening capacity may have been influenced by the fact that yeast counts did not stabilize and gradually increased along refreshments. This could indicate that sourdough can take longer to reach maturity. Regarding gluten sourdoughs, it is widely accepted that between 5 and 7 days of sourdough propagation may be necessary for it to achieve maturity (Ercolini et al., 2013). On the other hand, gluten-free sourdoughs prepared with different pseudocereals have been reported to achieve maturity within 3 and 7 days (Sterr et al., 2009; Rizzello et al., 2016). Further research is needed to know when ripe sourdough is achieved. Current results are difficult to compare because studies follow different recipes (fermentation times and temperatures, cold blocking, percentage of previous dough, etc.). In addition, most existing studies evaluate maturity of fermented dough through $\mathrm{pH}$, TTA and LAB, but do not perform yeast controls.

After this experimental laboratory study, and given the characteristics of the gluten-free sourdough obtained, it would be appropriate to test its response by using it in bakery products or others to evaluate its organoleptic contribution. Obtaining and maintaining a well-conducted spontaneous sourdough -with regard to a sourdough initiated with starters- would provide organoleptic specificity to the products made with it. Furthermore, this procedure could easily be scaled up to a 
higher level of production in a specific gluten-free product workshop where some parameters could be considered (e.g. blocking). Nevertheless, it would be necessary to maintain the test conditions, keeping fermentation time at $30{ }^{\circ} \mathrm{C}$ to reach the required $\mathrm{pH}$. This work offers insight into the behavior of gluten-free sourdough providing a proposal to prepare a spontaneous gluten-free sourdough elaborated with a pseudocereal flour mix composed of amaranth, buckwheat and quinoa. The proposal expands the alternatives that currently exist in the use of sourdough in glutenfree breads and other products, mainly introducing spontaneous fermentation.

\section{References}

Akinola SA and Osundahunsi OF. (2017) Lactic acid bacteria and yeast diversities in spontaneous fermented milled sourdoughs. Journal of Microbiology, Biotechnology and Food Science 6(4), 1030-1035. doi: 10.15414/jmbfs.2017.6.4.1030-1035.

Arendt E, Moroni A and Zannini E. (2011) Medical nutrition therapy: use of sourdough lactic acid bacteria as a cell factory for delivering functional biomolecules and food ingredients in gluten free bread. Microbial Cell Factories 10 (Suppl 1). S15. doi: 10.1186/1475-2859-10-S1-S15.

Aguilar N, Albanell E, Miñarro B, et al., (2016) Chestnut flour sourdough for gluten-free bread making. European Food Research and Technology 242, 1795-1802. doi: 10.1007/s00217-0162679-z.

Aslankoohi E, Herrera-Malaver B, et al., (2016) Non-Conventional Yeast Strains Increase the Aroma Complexity of Bread. PLOS ONE October 24. doi: 10.1371/journal.pone.0165126.

Brandt MJ, Hammes WP and Gänzle MG. (2004) Effects of process parameters on growth and metabolism of Lactobacillus sanfranciscensis and Candida humilis during rye sourdough fermentation. European Food Research and Technology 218, 333-338. doi: 10.1007/s00217-0030867-0.

Campo E, Del Arco L, Urtasun L, et al., (2016) Impact of sourdough on sensory properties and consumers' preference of gluten-free breads enriched with teff flour. Journal of Cereal Science 67, 75-82. http://dx.doi.org/10.1016/j.jcs.2015.09.010. 
Cappa C, Lucisano M, Raineri A, et al., (2016) Gluten-Free Bread: Influence of Sourdough and Compressed Yeast on Proofing and Baking Properties. Foods 5(4), 69. doi: 10.3390/foods5040069.

Capriles VD, Dos Santos FG and Arêas JAG. (2016) Gluten-free breadmaking: improving nutritional and bioactive compounds. Journal of Cereal Science 67(1), 83-91. doi: 10.1039/C5FO01264C.

Catassi C and Fasano A. (2008) Celiac disease. Current Opinion in Gastroenterology 24(6), 687691. doi: 10.1097/MOG.0b013e32830edc1e.

Collar C, Conte P, Fadda C et al., (2015) Gluten-free dough-making of specialty breads: Significance of blended starches, flours and additives on dough behaviour. Food Science and Technology International 21(7), 523-536. doi: 10.1177/1082013214552862.

Commission Regulation (EC) nº41/2009. Official Journal of the European Union, 21.1.2009, concerning the composition and labelling of foodstuffs suitable for people intolerant to gluten.

Curiel JA, Cosa R, Centomani I, et al., (2015) Exploitation of the nutritional and functional characteristics of traditional Italian legumes: The potential of sourdough fermentation. International Journal of Food Microbiology 196, 51-61. http://dx.doi.org/10.1016/j.ijfoodmicro.2014.11.032.

Di Cagno R, Rizzello CG, De Angelis M, et al., (2008) Use of selected sourdough strains of Lactobacillus for removing gluten and enhancing the nutritional properties of gluten-free bread. Journal of Food Protection 7, 1491-1795. doi: 10.4315/0362-028x-71.7.1491

Ercolini D, Pontonio E, De Filippis F, et al., (2013) Microbial ecology dynamics during rye and wheat sourdough preparation. Applied Environmental Microbiology 79, 7827-7836. doi: 10.1128/AEM.02955-13.

Galle S, Schwab C, Dal Bello F, et al., (2012) Influence of in-situ synthesized exopolysaccharides on the quality of gluten-free sorghum sourdough bread. International Journal of Food Microbiology 155(3), 105-112. doi: 10.1016/j.ijfoodmicro.2012.01.009. 
Gordún E, Del Valle LJ, Ginovart M, et al., (2015) Comparison of the microbial dynamics and biochemistry of laboratory sourdoughs prepared with grape, apple and yogurt. Food Science and Technology International, 21(6), 428-439. https://doi.org/10.1177/1082013214543033.

Gordún E, Puig A, Piñol L, et al., (2017) Identification of yeast isolated from laboratory sourdoughs prepared with grape, apple, and yogurt. Journal of Microbiology, Biotechnology and Food Sciences, 7(4), 399-403. doi: 10.15414/jmbfs.2018.7.4.399-403.

Hager AS, Wolter A, Jacob F, et al., (2012) Nutritional properties and ultra-structure of commercial gluten-free flours from different botanical sources compared to wheat flours. Journal of Cereal Science 56, 239-247. https://doi.org/10.1016/j.jcs.2012.06.00.5.

Hammes WP, Brandt MJ, Francis KL, et al., (2005) Microbial ecology of cereal fermentations. Trends in Food Science \&Technology 16, 4-11. https://doi.org/10.1016/j.tifs.2004.02.010.

Harth H, Van Kerrebroeck S and De Vuyst L. (2016) Community dynamics and metabolite target analysis of spontaneous, backslopped barley sourdough fermentations under laboratory and bakery conditions. International Journal of Food Microbiology 228, 22-32. doi: 10.1016/j.ijfoodmicro.2016.04.011.

Hassan YI, Zhou T and Bullerman LB. (2016) Sourdough lactic acid bacteria as antifungal and mycotoxin-controlling agents. Food Science and Technology International 22(1), 79-90. https://doi.org/10.1177/1082013214565722.

Hüttner EK and Arendt EK. (2010) Recent advances in gluten-free baking and the current status of oats. Trends in Food Science \& Technology 21(6), 303-312. https://doi.org/10.1016/j.tifs.2010.03.005.

Karaman K, Sagdic O and Durak ZM. (2018) Use of phytase active yeasts and lactic acid bacteria isolated from sourdough in the production of whole wheat bread. LWT-Food Science and Technology 91, 557-567. https://doi.org/10.1016/j.lwt.2018.01.055.

Lhome E, Lattanzi A, Dousset X, et al., (2015) Lactic acid bacterium and yeast microbiotas of sixteen French traditional sourdoughs. International Journal of Food Microbiology 215, 161-170. doi: 10.1016/j.ijfoodmicro.2015.09.015. 
Marti A, Bottega G, Franzetti L, et al., (2015) From wheat sourdough to gluten-free sourdough: a non-conventional process for producing gluten-free bread. International Journal of Food Science and Technology 50, 1268-1274. doi:10.1111/ijfs.12757.

Minervini F, De Angelis M, Di Cagno R, et al., (2014) Review. Ecological parameters influencing microbial diversity and stability of traditional sourdough. International Journal of Food Microbiology 171, 136-146. doi: 10.1016/j.ijfoodmicro.2013.11.021.

Montemurro M, Pontonio E, Gobbetti M, et al., (2019) Investigation of the nutritional, functional and technological effects of the sourdough fermentation of sproud flours. International Journal of Food Microbiology 302, 47-58. https://doi.org/10.1016/j.ijfoodmicro.2018.08.005.

Moroni AV, Dal Bell F and Arendt EK. (2009) Sourdough in gluten-free bread-making: An ancient technology to solve a novel issue? Food Microbiology, 26, 676-684. doi:10.1016/j.fm.2009.07.001.

Novotni D, Čukelj N, Smerdel B, et al., (2012) Glycemic index and firming kinetics of partially baked frozen gluten-free bread with sourdough. Journal of Cereal Science 55(2), 120-125. https://doi.org/10.1016/j.jcs.2011.10.008.

Ogunsakin OA, Banwo K, Ogunremi OR, et al., (2015) Microbiological and physicochemical properties of sourdough bread from sorghum flour. International Food Research Journal 22 (6), 2610-2618.

Picozzi C, Mariotti M, Cappa C, et al., (2015) Development of a Type I gluten-free sourdough. Letters in Applied Microbiology 62, 119-125 doi: 10.1111/lam.12525.

Rinaldi M, Paciulli M, Caligiani A, et al., (2017) Sourdough fermentation and chestnut flour in gluten-free bread: A shelf-life evaluation. Food chemistry 224, 144-152. http://dx.doi.org/10.1016/j.foodchem.2016.12.055.

Rizzello CG, Lorusso A, Montemurro M, et al., (2016) Use of sourdough made with quinoa (Chenopodium quinoa) flour and autochthonous selected lactic acid bacteria for enhancing the nutritional, textural and sensory features of White bread. Food Microbiology 56, 1-13. http://dx.doi.org/10.1016/j.fm2015.11.018. 
Rühmkorf C, Jungkunz S, Wagner M, et al., (2012) Optimization of homoexopolysaccharide formation by lactobacilli in gluten-free sourdoughs. Food Microbiology 32, 286-294. http://dx.doi.org/10.1016/j.fm.2012.07.002.

Salovaara H and Valjakka T. (1987) The effect of fermentation temperature, flour type and starter on the properties of sour wheat bread. International Journal of Food Science \& Technology 22, 591-597. https://doi.org/10.1111/j.1365-2621.1987.tb00527.x.

Siepmann FB, Ripari V, Waszczynskyj N, et al., (2018) Overwiew of sourdough technology: from production to marketing. Food Bioprocess Technology 11, 242-270. doi: 10.1007/s11947-0171968-2.

Sterr Y, Weiss A and Schmidt H. (2009) Evaluation of lactic acid bacteria for sourdough fermentation of amaranth. International Journal of Food Microbiology 136, 75-82. doi: 10.1016/j.ijfoodmicro.2009.09.006.

USDA Food Composition Databases. United States Department of Agriculture. Agricultural Research Service. Available at: https://ndb.nal.usda.gov/ndb/ (accessed 3 May 2018).

Van Kerrebroeck S, Casanova C, Bastos F, et al., (2016) A low pH does not determine the community dynamics of spontaneously developed backslopped liquid wheat sourdough but does influence their metabolite kinetics. International Journal of Food Microbiology 239, 54-64. doi: 10.1016/j.ijfoodmicro.2016.07.019.

Vogelmann SA, Seitter M, Singer U, et al., (2009) Adaptability of lactic acid bacteria and yeasts to sourdoughs prepared from cereals, pseudocereals and cassava and use of competitive strains as starters. International Journal of Food Microbiology 130, 205-212. doi:10.1016/j.ijfoodmicro.2009.01.020.

Walters LS and Thiselton MR. (1953) Utilization of lysine by yeast. Journal of the Institute of Brewing 5, 401-404. https://dx.doi.org/10.1002/j.2050-0416.1953.tb02736.x.

Witczak M, Ziobro R, Juszczak L et al., (2016) Starch and starch derivatives in gluten-free systems - A review. Journal of Cereal Science, 67(1), 46-57. doi: 10.1016/j.jcs.2015.07.007. 
Wolter, A, Hager, AS, Zannini, E, et al., (2014) Evaluation of exopolysaccharide producing Weissella cibaria MG1 strain for the production of sourdough from various flours. Food Microbiology 37, 44-50. http://dx.doi.org/10.1016/j.fm.2013.06.009. 


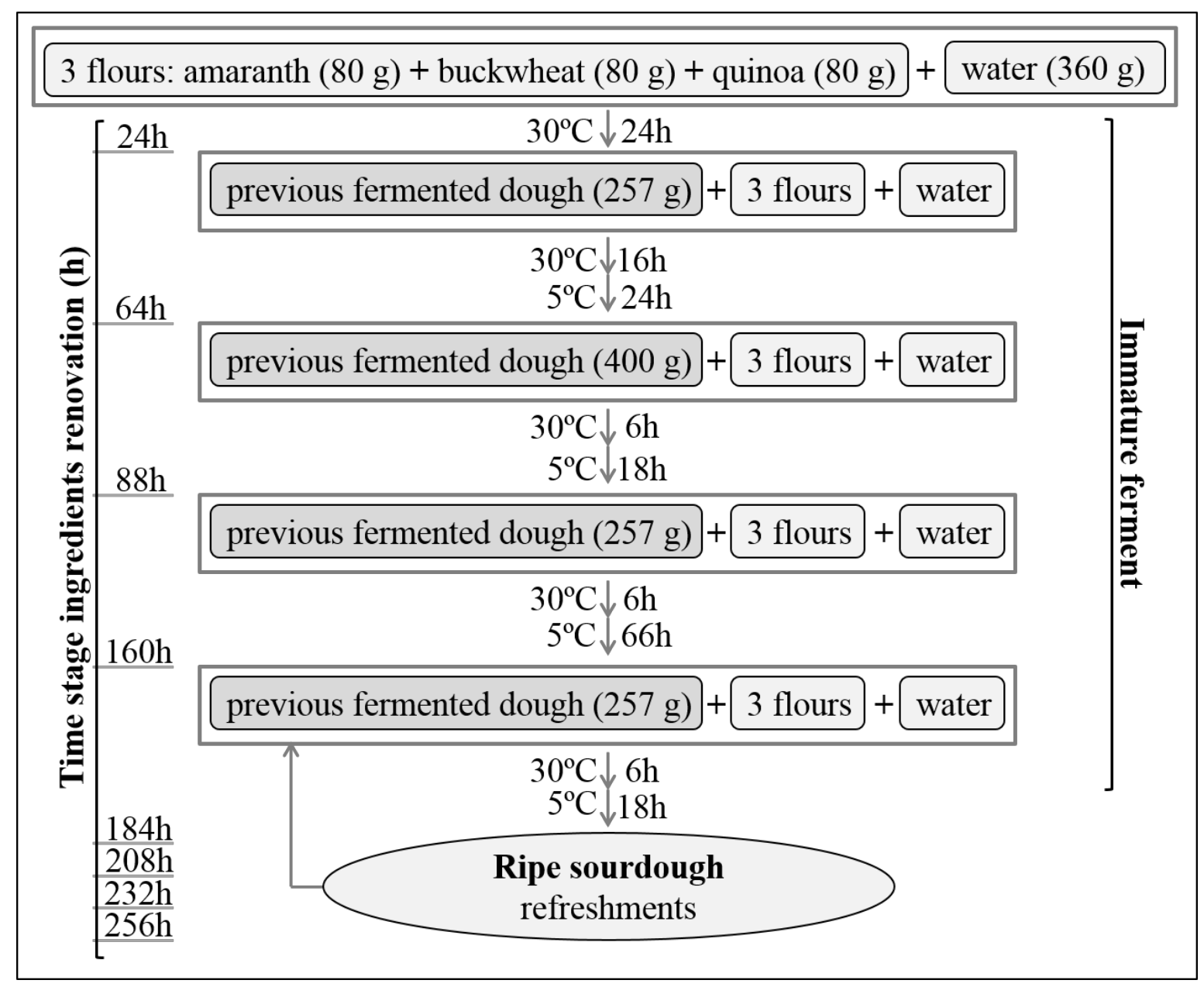

Figure 1. Flow chart resuming the protocol at laboratory scale of production of mature spontaneous gluten-free sourdough elaborated with a pseudocereal flour mix composed of amaranth, buckwheat and quinoa in equal proportions, and a constant dough yield of 250 . The quantity used of the previously fermented dough was $30 \%$ (w previous dough/w total obtained dough), except before the third stage fermentation when it was $40 \%$. 


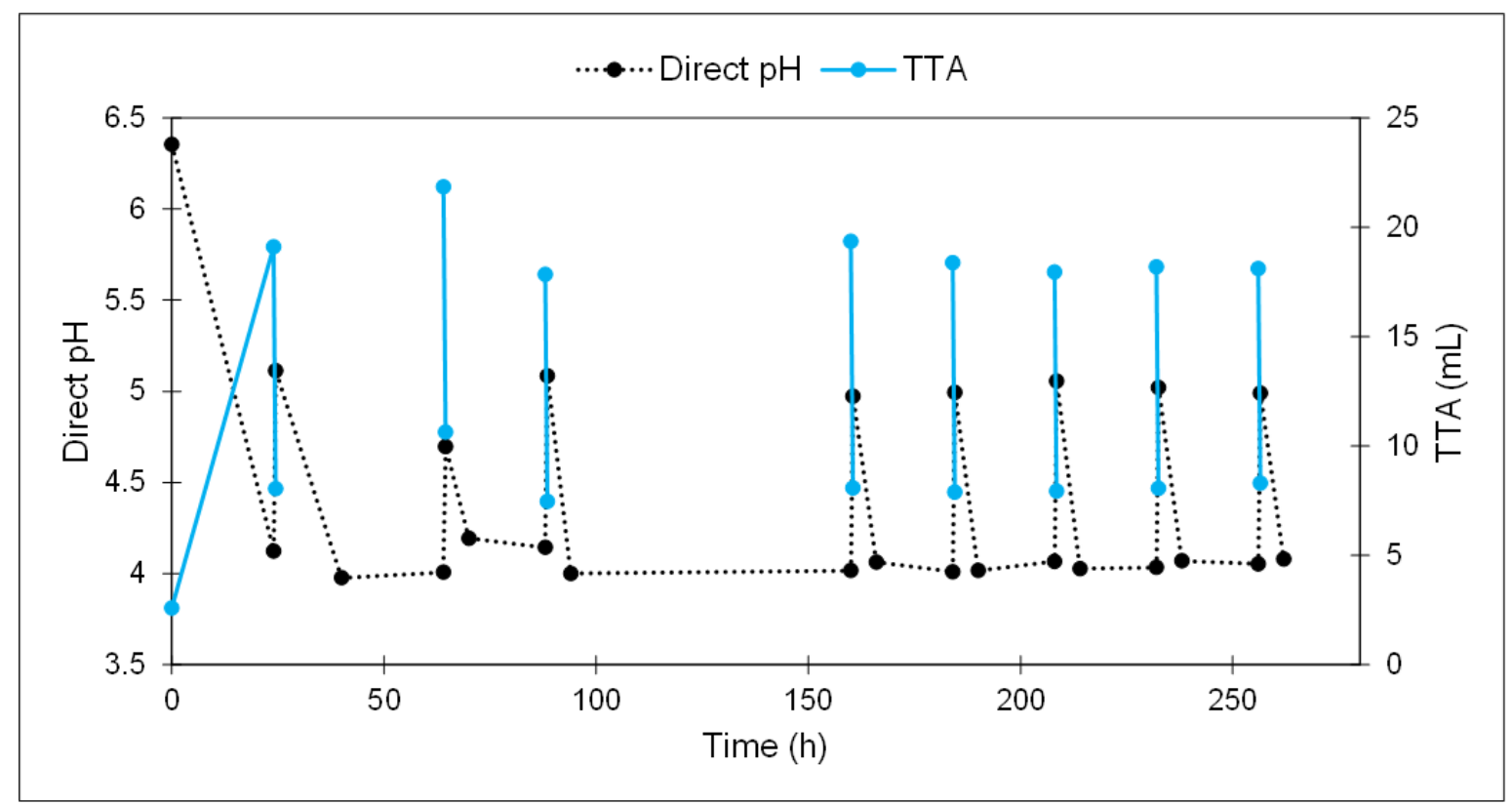

Figure 2. Evolution of direct $\mathrm{pH}$ and TTA throughout the experiment. TTA was expressed as $\mathrm{ml} \mathrm{NaOH} 0.1 \mathrm{~mol} / \mathrm{l}$ used to titrate a $10 \mathrm{~g}$ sample (blended with $90 \mathrm{ml}$ distilled water) to $\mathrm{pH}$ 8.5. The points are means of three experimental values. For all the Direct $\mathrm{pH}$ means the standard errors were less than 0.05 and for all the TTA means the standard errors were less than 0.4 . 


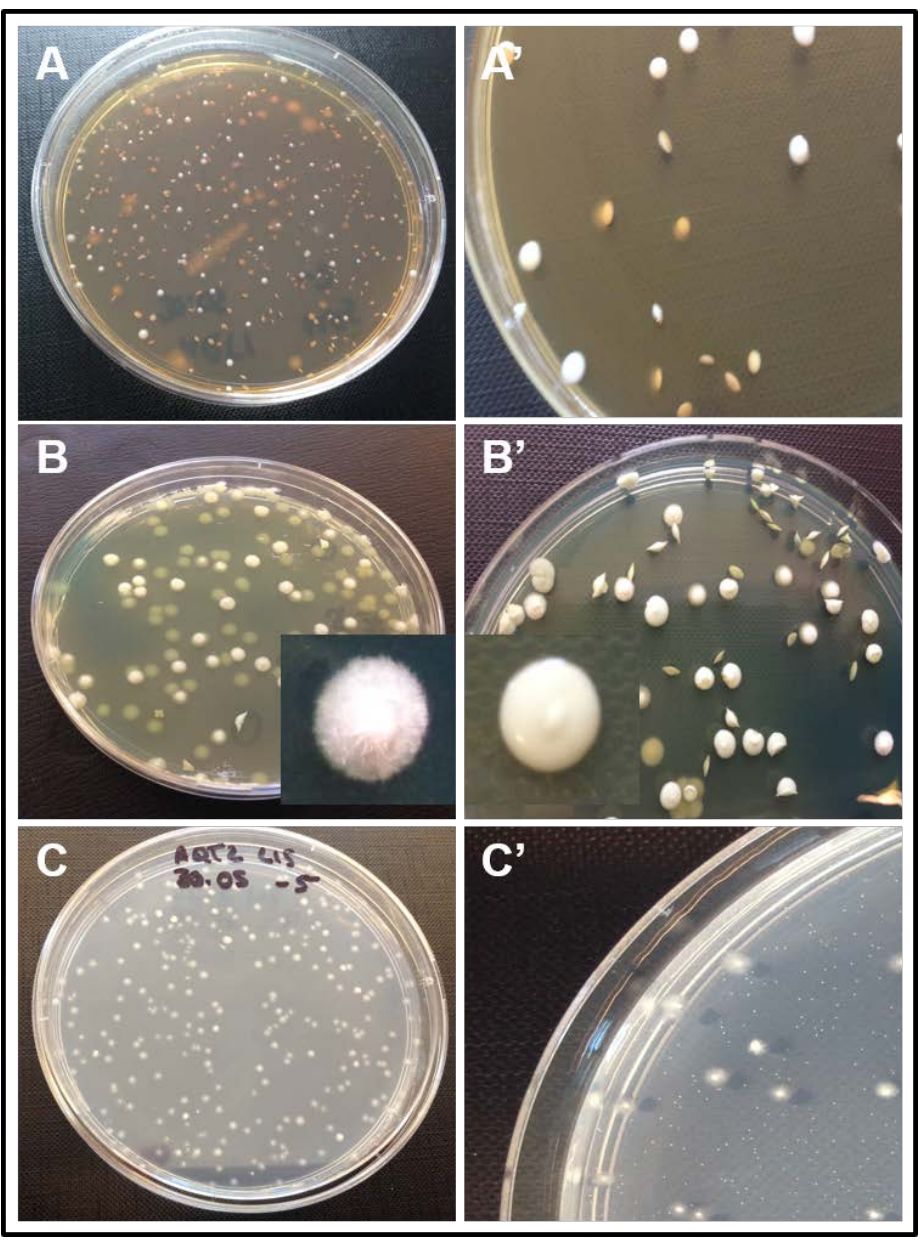

Figure 3. Details of colony morphologies in microbial populations of the lactic acid bacteria in MRS agar (A, A'); total yeasts in WL agar (plate with filamentous colonies dominant (B)), and plate with entire colonies dominant (B'); and non-Saccharomyces filamentous colonies yeasts in Lysine agar (C, C'). 


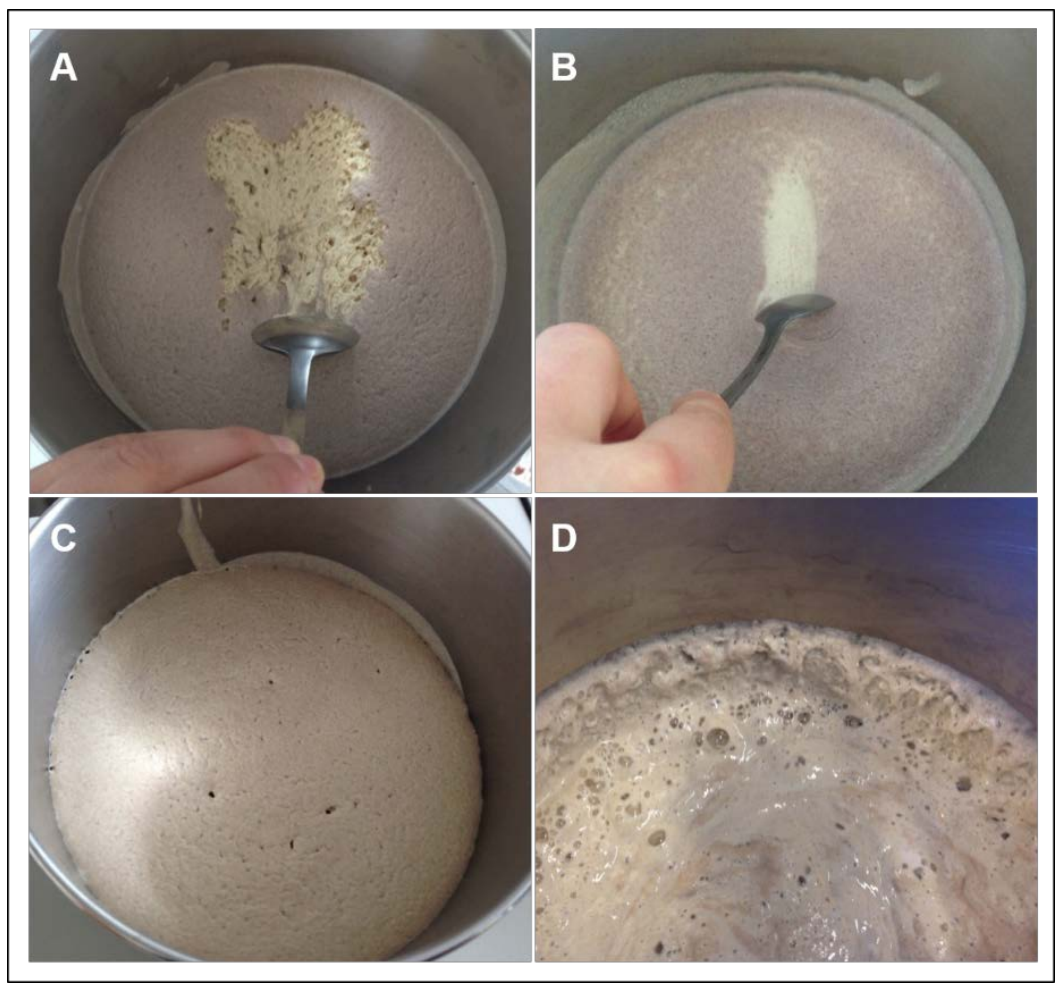

Figure 4. Aspect of immature ferment (A, B) and the ripe sourdough (C, D) elaborated with pseudocereal flours (amaranth, buckwheat and quinoa in equal proportions) and with a DY of 250. Immature ferment appearance after first $24 \mathrm{~h}$ fermentation at $30{ }^{\circ} \mathrm{C}(\mathrm{A})$, and after second renovation and $16 \mathrm{~h}$ fermentation at $30^{\circ} \mathrm{C}$ (B). Ripe sourdough phase appearance after some refreshments and fermentation $6 \mathrm{~h}$ at $30{ }^{\circ} \mathrm{C}$ (after the first refreshment (C), and after the third refreshment (D) of the experiment. 
Table 1. Means of the microbiological counts of lactic acid bacteria (LAB), total yeasts and nonSaccharomyces yeasts (Lysine positive yeast), and Lysine negative yeast (difference between total yeast and non-Saccharomyces yeast) expressed as Log CFU/g of the three samples of doughs, with the corresponding standard deviations (SD).

\begin{tabular}{lllll}
\hline Time $(\mathrm{h})$ & LAB & Total yeast & $\begin{array}{l}\text { Non- } \\
\text { Saccharomyces } \\
\text { yeast }\end{array}$ & $\begin{array}{l}\text { Lysine negative } \\
\text { yeast }\end{array}$ \\
\hline 24 & $9.54(0.14)$ & $4.64(0.18)$ & $4.62(0.17)$ & $3.39(0.39)$ \\
88 & $9.39(0.09)$ & $7.09(0.09)$ & - & - \\
160 & $9.72(0.11)$ & $7.46(0.09)$ & $7.44(0.12)$ & $4.19(3.64)$ \\
208 & $9.59(0.11)$ & $7.61(0.06)$ & $7.54(0.02)$ & $6.76(0.32)$ \\
256 & $9.62(0.08)$ & $8.21(0.24)$ & $7.51(0.19)$ & $8.05(0.39)$ \\
\hline
\end{tabular}

